\title{
Presenting new models to determine subgrade reaction modulus (Ks) for optimizing foundation calculations in coarse grained soils
}

\author{
Pouya Salari (Main Author) \\ Department of Geology, Faculty of Science, Ferdowsi University of Mashhad \\ 9177948974, Mashhad (Iran) \\ pouya.salari90@gmail.com
}

Naser Hafezi Moghaddas (Corresponding Author)

Department of Geology, Faculty of Science, Ferdowsi University of Mashhad

9177948974, Mashhad (Iran)

nhafezi@um.ac.ir

\section{Gholam Reza Lashkaripour}

Department of Geology, Faculty of Science, Ferdowsi University of Mashhad 9177948974, Mashhad (Iran)

lashkaripour@um.ac.ir

\section{Mohammad Ghafoori}

Department of Geology, Faculty of Science, Ferdowsi University of Mashhad 9177948974, Mashhad (Iran)

ghafoori@um.ac.ir

\author{
Manuscript Code: 13956 \\ Date of Acceptance/Reception: 25.07.2020/26.09.2019 \\ DOI: $10.7764 / R D L C .19 .2 .235$
}

\section{Abstract}

Subgrade reaction modulus (Ks) is one of the most important soil parameters to perform structural calculations and analysis. Ks directly affects the determination of dimensions and reinforcement of foundations. Therefore, its exact and accurate determination is of significant importance in terms of economy and safety, especially in large structures. To calculate thecoefficient, it is possible to use either the previously presented experimental relations or directly from field tests such as plate load tests. In the present study, 36 plate load tests (PLTs) were performed on the rigid plates with $20 \mathrm{~cm}, 30 \mathrm{~cm}$ and $45 \mathrm{~cm}$ diameters (12 tests on each plate) on coarse-grained sediments of the west of Mashhad, Iran. Then the results were analyzed and a new equation was presented to determine Ks by considering soil and foundation properties no need to costly tests. Then, a new model was presented to generalize the results of plate load tests to actual dimensions of the foundation. Also, the obtained equation and model were validated and results were compared with previous relations and tests outputs.

Keywords: subgrade reaction modulus, plate load test, coarse-grained sediments, foundation properties, results generalization.

\section{Introduction}

The condition and properties of the soils in the project site have always been a matter of concern in the design and analysis of the structures (Das, 2016). The engineering properties of the surficial deposits not only play an important role in determining the bearing capacity and lateral pressure during the excavation, but also are effective in the optimal design of the structure and executive operations including foundation calculations, retaining walls, blotting and planning (Wang \& Kulhawy, 2008). The subgrade reaction modulus (Ks) is one of the most important parameters that play a key role in foundation calculations in terms of scope, dimension and reinforcement (Eslami, 2006).

The accurate and reliable determination of this parameter is of central importance in solving the problems related to settlement and optimal design of the structure, especially in tall structures can facilitate and optimize calculation of structure elements in terms of weight and economy (Wang, 2009).

Ks is a conceptual relation between soil pressure and settlement, which has an important role in calculation of foundation elements, strip and raft foundations and piles (Eq.1).

$$
\mathrm{Ks}=\frac{q}{\delta}
$$

Where $q$ is applied pressure and $\delta$ is the settlement caused by the applied load.

To estimate Ks, various experimental equations have been presented by different researchers (Table 1) (Bowels, 2001). 

No. Researcher
Equation
No. Researcher
Equation

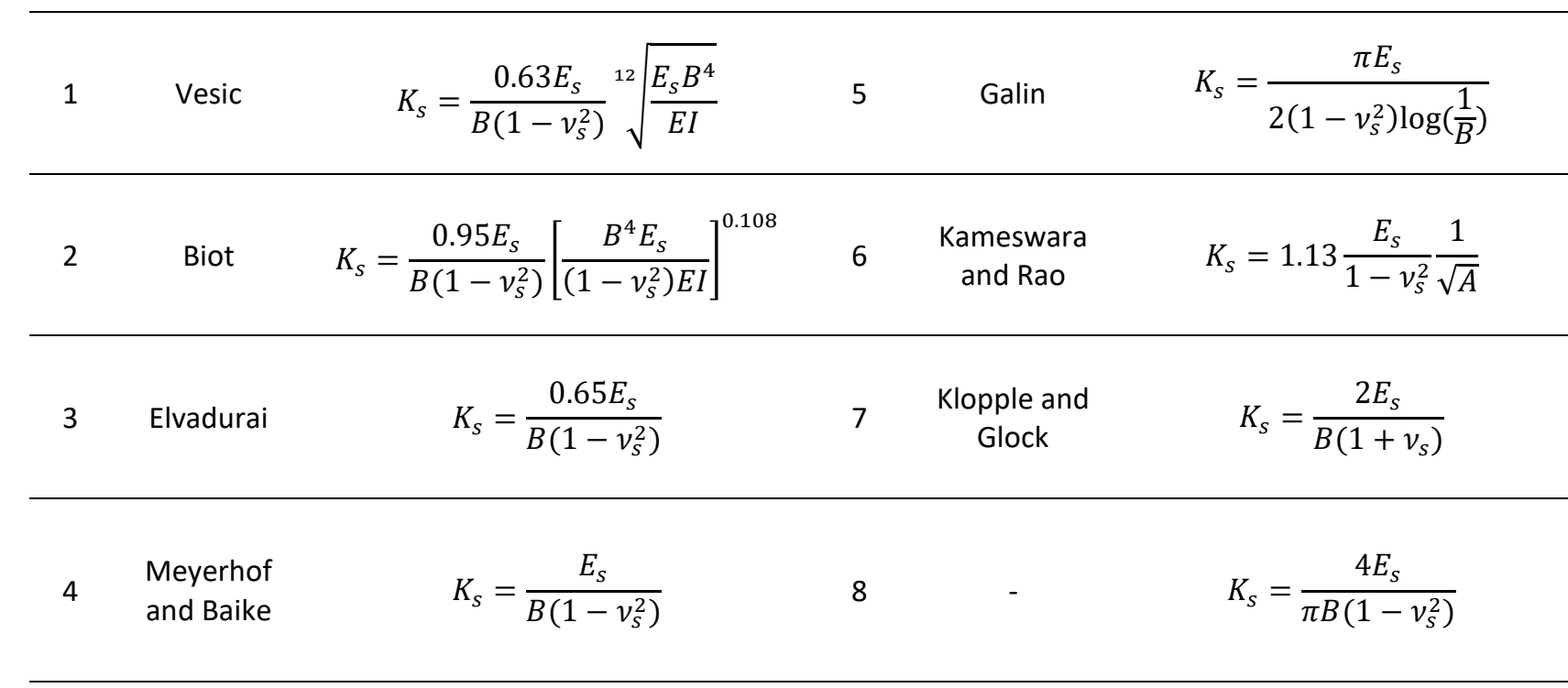

Where $\mathrm{E}_{\mathrm{s}}$ is soil Young's modulus, $v_{\mathrm{s}}$ is soil Poisson's ratio, $\mathrm{A}$ is foundation area, $\mathrm{B}$ is foundation width or itsequivalent diameter and $\mathrm{El}$ is foundation flexural rigidity.

Also, various tests, such as triaxial, consolidation, pressure meter and plate load test are recommended to determine the Ks, which plate load test is more reliable and more popular of these tests (Mollahasani, 2008).

\section{Description of the problem}

The existence of different equations presented to determine the subgrade reaction modulus (Ks) by different scientists makes it difficult to select the appropriate relation. Also, if in situ or laboratory testing is performed, due to differences in modeling and actual foundations, the results are not fully reliable.

In this study, by performing 36 plate load tests on coarse-grained sediments in the west of Mashhad with different steel rigid plates, a comprehensive equation for calculating the subgrade reaction modulus of soils based on modulus of elasticity of soils, shape and dimensions of foundations was presented.Also, the effect of foundation area on Ks was evaluated and a new mathematical model was presented to generalize the results to real foundation's dimensions in case of performing plate load test.

\section{Methodology}

There are several methods to carry out the Plate load tests (Table 2) (Water Resources Management Department of the Ministry of Energy, 2005):

In the present study, incremental loading was used according to the type of soil and final goal. By this, 12 tests were performed on each of the plates with diameters of $20 \mathrm{~cm}, 30 \mathrm{~cm}$ and $45 \mathrm{~cm}$ (totally 36 tests) using a plate-load jack. To have more valid results, the PLTs were performed after removing surficial soils and placing and leveling the plates on the subsoil. In addition to perform PLT with the power of $500 \mathrm{KN}$ jack and the circular rigid plates with diameters of 20 , 30 , and $45 \mathrm{~cm}$, a loaded truck was used to apply the reaction (Figure 1). 
Table 2. PLTs methods (Water Resources Management Department of the Ministry of Energy, 2005)

\begin{tabular}{cl} 
Table 2. PLTs methods (Water Resources Management Department of the Ministry of Energy, 2005). \\
\hline Number & \multicolumn{1}{c}{ Plate load test methods } \\
\hline 1 & $\begin{array}{l}\text { The constant settlement rate: In this method, the settlement rate is selected based on soil penetrability } \\
\text { coefficient and the size of the loading plate. As an approximate pattern, settlement rate can be } \\
\text { considered to be } 2.5 \mathrm{~mm} / \mathrm{min} \text {. This method is suitable for fine-grained cohesive soils. }\end{array}$ \\
\hline 2 & $\begin{array}{l}\text { Loading for creep: This method is used when the creep behavior of the soil is of interest or the structure } \\
\text { is very sensitive to settlement. }\end{array}$ \\
3 & $\begin{array}{l}\text { Incremental loading: The final load is predicted as a multiple of allowable strength and loading stages } \\
\text { are determined. In each loading stage, the settlement rate is measured in minutes } 1,2,4, \text { and } 8 . \text { This } \\
\text { method can be performed on all types of soil. }\end{array}$ \\
& $\begin{array}{l}\text { Cyclic Loading: This method can be used when the cyclic performance is considered. For example, in } \\
\text { the airport and main road pavement, cyclic loading is performed to fix the settlement after applying } \\
\text { the loading process several times. }\end{array}$ \\
& $\begin{array}{l}\text { Direct design loading: In this method, to consider the long-term behavior of the materials under } \\
\text { foundation, the pressure applied to plate is selected by modeling the conditions of construction and } \\
\text { operation of the structure. }\end{array}$ \\
\hline
\end{tabular}

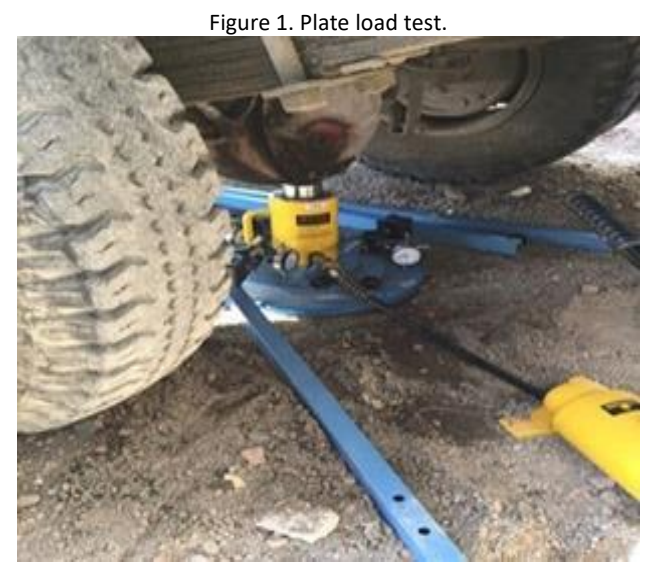

The device was calibrated by national standard organization with coverage factor $k=2$ correspond to confidence level 95\% and the required data were collected after installing equipment, applying load on a steel plate and recording load and settlement rate simultaneously by load and settlement gauges (Barmenkova \& Matweeda, 2015).

The loading process was incremental and its incremental steps were about one-fifth to one-fourth of the final estimated load.

The load was controlled in the desired increment and the next load increment was applied under the previous load after the settlement reached a stable state.

After applying the final load, at least 2 unloading stages were performed.

Moreover, for each of the studied areas, in-situ density test was carried out using sand bottle method. Next, in the laboratory, the dominant soil texture in the studied depth was determined.

\section{Soil Properties}

Table 3 presents the soil properties of 12 studied stations ( $\gamma_{w}$ and $\gamma_{d}$ means wet and dry unit weights). The samples were taken from about $0.2 \mathrm{~m} \_1 \mathrm{~m}$ depth that can be presumed as load effect limit and bears only $5 \%$ of surficial stress based on Boussinesq studies on the range of circularly stress effect (Das, 2016). As can be seen, the dominant texture of the soil is coarse-grained gravel and silty sand. 
Table 3. The properties of the studied soils (unified classification system).

\begin{tabular}{llllllll}
\hline Station & $\gamma_{w}\left(\frac{g r}{c m^{3}}\right)$ & $\gamma_{d}\left(\frac{g r}{\mathrm{~cm}^{3}}\right)$ & Type & station & $\gamma_{w}\left(\frac{g r}{\mathrm{~cm}^{3}}\right)$ & $\gamma_{d}\left(\frac{g r}{\mathrm{~cm}^{3}}\right)$ & Type \\
\hline 1 & 1.85 & 1.81 & SW & 7 & 1.88 & 1.81 & SM \\
2 & 1.86 & 1.80 & GC_GM & 8 & 1.89 & 1.79 & GM \\
3 & 1.86 & 1.79 & SP_SM & 9 & 1.79 & 1.75 & GM \\
4 & 1.89 & 1.82 & GP & 10 & 1.82 & 1.78 & GM \\
5 & 1.84 & 1.80 & GP_GM & 11 & 1.83 & 1.76 & SP_SM \\
6 & 1.89 & 1.81 & GM & 12 & 1.79 & 1.75 & SP_SM \\
\hline
\end{tabular}

\section{Ks and Es Calculations}

After performing PLTs and collecting the required data, by considering the following items, the Ks was calculated for each station using the pressure-settlement curve:

- Loading did not continue until the soil rupture.

- The applied stress on plates and settlement were measured.

- Loading was performed on coarse-grained soils with low cohesion.

The Ks values were calculated according to Wilun \& Starzewski (1972) method (Mollahasani, 2008).

This method is applied when the unloading is done before reaching the final strength of soil. In this process, equal intervals ( 3 to 4 intervals) are selected on the vertical line drawn on a pressure-settlement curve. Then, horizontal lines are drawn from the intervals to cross the curve. Next, vertical lines are drawn from the intersection point to cross the horizontal axis (pressure axis) and lines with a $45^{\circ}$ angle are drawn from the intersection point of vertical lines and pressure axis to cross the adjacent vertical lines. Finally, from the obtained points, a direct line is drawn to intersect the pressure axis. This point shows the final strength of the soil that presume as Ks values (Figure 2).

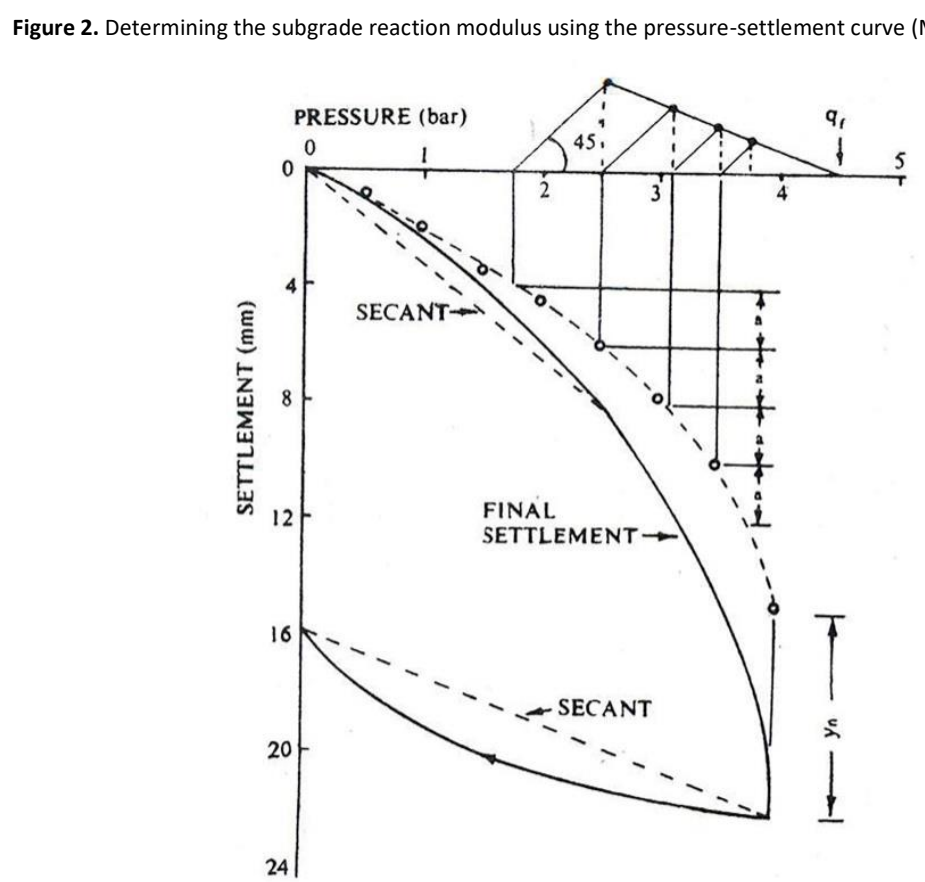

Due tothe dominant texture of the soil (coarse-grained gravel and silty sand) in approximately dried studied soils, suction was not considered and $\delta^{\prime}=\delta$ (Fredlund, Rahardjo, \& Fredlund, 2012).

To calculate Es, most of the researchers have suggested Eq. 2 due to lack of linear area in the pressure-settlement curve for soils in the plate load test (PLT).

$$
E=\frac{q}{\rho} \cdot B\left(1-\mu^{2}\right) \cdot I_{S}
$$


Where $E$ is soil elasticity modulus, $q$ is the pressure applied on the loading plate, $\rho$ is the plate settlement, $B$ is foundation width or its equivalent diameter, $\mu$ is soil poisson's ratio and $I_{s}$ is the plate shape factor.

The shape factor of the circular rigid foundation was suggested to be 0.79 (Das, 2016).Table 4 presents the Es values and variations of Ks based on plate diameters. As seen, an increase in diameter and plate area results in a decrease in Ks.

\begin{tabular}{|c|c|c|c|c|}
\hline Station & $\begin{array}{c}\text { Ks }\left(\frac{\mathrm{kg}}{\mathrm{cm}^{3}}\right) \\
(20 \mathrm{~cm})\end{array}$ & $\begin{array}{l}\mathrm{Ks}\left(\frac{\mathrm{kg}}{\mathrm{cm}^{3}}\right) \\
(30 \mathrm{~cm})\end{array}$ & $\begin{array}{l}\mathrm{Ks}\left(\frac{\mathrm{kg}}{\mathrm{cm}^{3}}\right) \\
(45 \mathrm{~cm})\end{array}$ & Es $\left(\frac{\mathrm{kg}}{\mathrm{cm}^{2}}\right)$ \\
\hline 1 & $12.7 \frac{\mathrm{Kg}}{\mathrm{cm}^{3}}$ & $7.2 \frac{\mathrm{Kg}}{\mathrm{cm}^{3}}$ & $4.6 \frac{\mathrm{Kg}}{\mathrm{cm}^{3}}$ & 185 \\
\hline 2 & $11 \frac{\mathrm{Kg}}{\mathrm{cm}^{3}}$ & $6.3 \frac{\mathrm{Kg}}{\mathrm{cm}^{3}}$ & $4.3 \frac{\mathrm{Kg}}{\mathrm{cm}^{3}}$ & 170 \\
\hline 3 & $11.9 \frac{\mathrm{Kg}}{\mathrm{cm}^{3}}$ & $6.9 \frac{\mathrm{Kg}}{\mathrm{cm}^{3}}$ & $4.5 \frac{\mathrm{Kg}}{\mathrm{cm}^{3}}$ & 180 \\
\hline 4 & $13.5 \frac{\mathrm{Kg}}{\mathrm{cm}^{3}}$ & $7.1 \frac{\mathrm{Kg}}{\mathrm{cm}^{3}}$ & $4.8 \frac{\mathrm{Kg}}{\mathrm{cm}^{3}}$ & 190 \\
\hline 5 & $11.5 \frac{\mathrm{Kg}}{\mathrm{cm}^{3}}$ & $6.8 \frac{\mathrm{Kg}}{\mathrm{cm}^{3}}$ & $4.1 \frac{\mathrm{Kg}}{\mathrm{cm}^{3}}$ & 170 \\
\hline 6 & $16.5 \frac{\mathrm{Kg}}{\mathrm{cm}^{3}}$ & $8.3 \frac{\mathrm{Kg}}{\mathrm{cm}^{3}}$ & $6 \frac{\mathrm{Kg}}{\mathrm{cm}^{3}}$ & 240 \\
\hline 7 & $14.2 \frac{\mathrm{Kg}}{\mathrm{cm}^{3}}$ & $7.8 \frac{\mathrm{Kg}}{\mathrm{cm}^{3}}$ & $5.2 \frac{\mathrm{Kg}}{\mathrm{cm}^{3}}$ & 190 \\
\hline 8 & $13.8 \frac{\mathrm{Kg}}{\mathrm{cm}^{3}}$ & $7.4 \frac{\mathrm{Kg}}{\mathrm{cm}^{3}}$ & $5.1 \frac{\mathrm{Kg}}{\mathrm{cm}^{3}}$ & 200 \\
\hline 9 & $16 \frac{\mathrm{Kg}}{\mathrm{cm}^{3}}$ & $8.2 \frac{\mathrm{Kg}}{\mathrm{cm}^{3}}$ & $5.9 \frac{\mathrm{Kg}}{\mathrm{cm}^{3}}$ & 210 \\
\hline 10 & $13 \frac{\mathrm{Kg}}{\mathrm{cm}^{3}}$ & $7.3 \frac{\mathrm{Kg}}{\mathrm{cm}^{3}}$ & $5 \frac{\mathrm{Kg}}{\mathrm{cm}^{3}}$ & 200 \\
\hline 11 & $11 \frac{\mathrm{Kg}}{\mathrm{cm}^{3}}$ & $6.6 \frac{\mathrm{Kg}}{\mathrm{cm}^{3}}$ & $4.6 \frac{\mathrm{Kg}}{\mathrm{cm}^{3}}$ & 175 \\
\hline 12 & $15.9 \frac{\mathrm{Kg}}{\mathrm{cm}^{3}}$ & $8.5 \frac{\mathrm{Kg}}{\mathrm{cm}^{3}}$ & $5.7 \frac{\mathrm{Kg}}{\mathrm{cm}^{3}}$ & 220 \\
\hline
\end{tabular}

After considering the soil stiffness and plate diameter, the geometrical properties of the foundation was evaluated by calculating the moment of inertia of different circular rigid steel plates according to $I=\frac{\pi}{4} r^{4}$, where, $r$ is the radius of the plate.

Discussion

\section{Presenting a New Equation}

The moment of inertia of foundation, Es and the width of the foundation were used to obtain Eq. 3 in SI system. The correlation coefficient of the equation is close to 1 and $P$-value $<0.001$ shows the high validity of the presented equation (Isotalo, 2001).

$$
\log \left(K_{s}\right)=0.911 \times \log (B)+0.871 \times \log (E s)-0.532 \times \log (I)
$$

F-statistic: 9699 on 3 and 33 DF, p-value: $<0.001$

Multiple R-squared: 0.998

Figure 3 shows the results of comparing the present equation with real data and equations that presented by "Vesic (1972)" and "Bowels (1988)" as the two most used relations (Bowels, 2001). In mentioned comparison, $E=2 \times$ $10^{6} \frac{\mathrm{kg}}{\mathrm{cm}^{2}}$ and $v_{s}=0.3$ were respectively considered for rigid steel plates and studied soils (Sepad Andish, 2015). It is observed that the results of the proposed equation in the linear area are 1:1, which indicates the high accuracy of the equation in predicting Ks. Although the "Bowels (1988)" relation has a proper prediction for low and medium values, in higher values such as $8 \mathrm{~kg} / \mathrm{cm}^{3}$ and more, the prediction of Ks is low. Besides, "Vesic (1972)" shows low values and it is not very accurate for coarse-grained soils. 


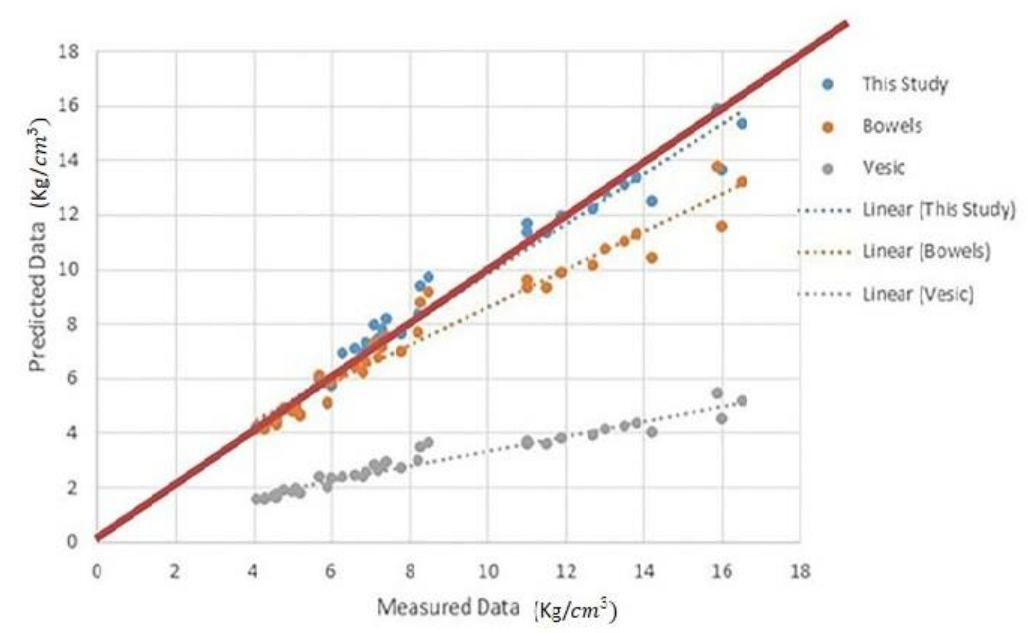

Eq. 3 can be simplified by conducting mathematical processes (Eq. 4).

$$
K_{S}=\frac{B^{0.91} \times E S^{0.87}}{\sqrt{I}}(4)
$$

\section{Generalized Model}

\section{Ks and Foundation's Area Relation}

Then, a new model was developed to generalize the results of the experiments to real foundations due to the difference in the size of the real foundation and the loading plate.

In order to obtain the best relation between Ks and foundation area (S), the statistical operations were fitted by averaging the results of PLTs on different plate sizes and areas (Figure 4).

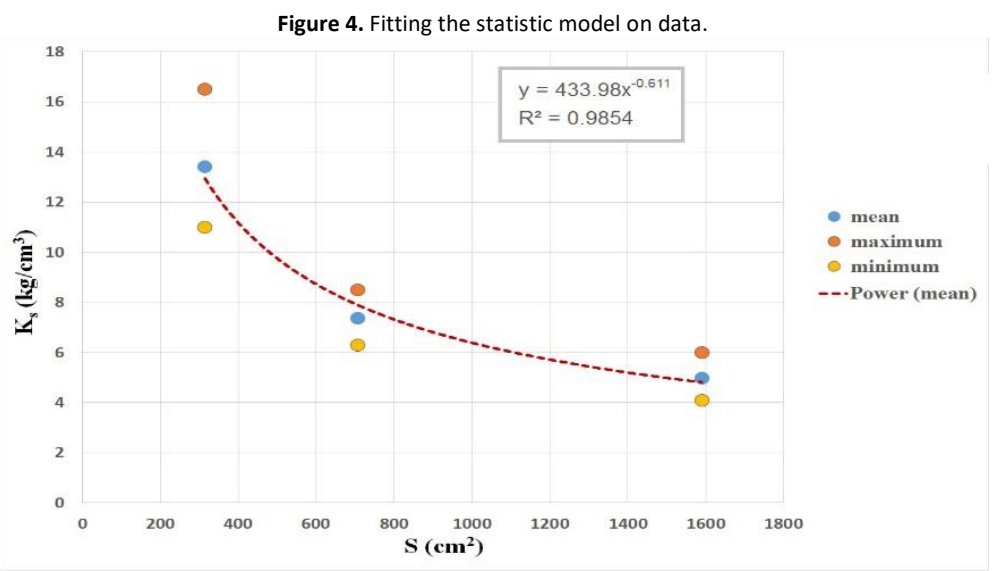

According to Figure 4, the power model can establish a relation between the parameters of Ks and foundation area (S) with high accuracy. The obtained coefficient of determination $\left(R^{2}=0.98\right)$ indicates the high accuracy of the power model in making a relation between Ks and foundation area (Winters, Winters, \& Amedee, 2010).

\section{Comparing Results with Previous Equations}

Considering the equations in Table 1 and substituting $\mathrm{I}=\frac{\pi}{4} \mathrm{r}^{4}$ ( $\mathrm{r}$ is radius) and $\mathrm{L}=\mathrm{B}$ in circular rigid plates, the previous experimental equations showed the reverse relation between $\mathrm{Ks}$ and diameter of circular plates, which is known as the 
foundation width. Since the dimensions of the loading plates and the actual foundation are typically different, the generalization of the results for real sizes is done based on the same inverse ratio.

Figure 5 shows the comparison between tests results, table 1 experimental equations and this paper obtained curve (Figure 4). By substituting $v_{s}=0.3$ for coarse-grained sediments in the west of Mashhad and considering a $30 \mathrm{~cm}$ diameter and $706 \mathrm{~cm}^{2}$ area plate as a common one to carry out PLTs, $E_{s}$ values were calculated. Then, by substituting $E_{S}$ in table 1 equations, $K_{s}$ were measured for other dimensions. It is observed that this study obtained curve indicates the high accuracy in predicting real Ks for different foundations area. Also, except Galin relation, using most of table 1 equations and this paper obtained curve leads to close results.

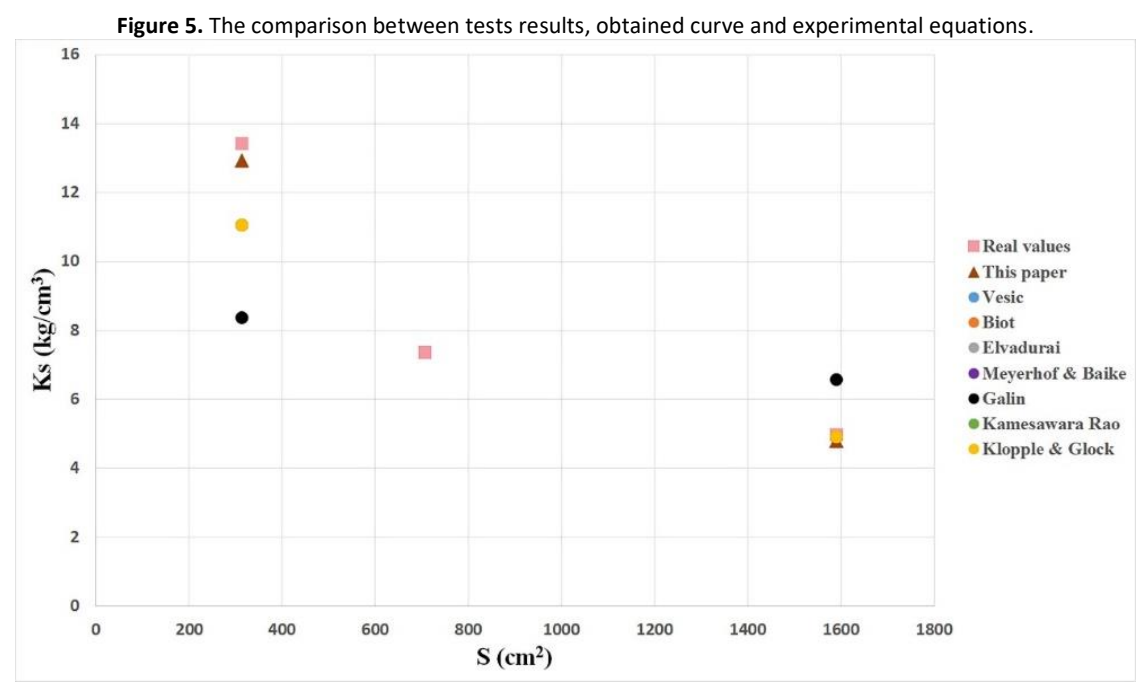

In table 5, experimental equations, this paper obtained curve and PLTs values were compared and error rate was computed. Results show very close estimation of this paper obtained curve and most of previous equations.

Table 5. The comparison between tests results, obtained curve and experimental equations.

\begin{tabular}{lcccc}
\multicolumn{5}{c}{ Table 5. The comparison between tests results, obtained curve and experimental equations. } \\
\hline \multicolumn{1}{c}{ Researcher } & B & Ks & $\mathrm{S}$ & \\
\hline Vesic & $(\mathrm{cm})$ & $\left(\frac{\mathrm{kg}}{\mathrm{cm}^{3}}\right)$ & $\left(\mathrm{cm}^{2}\right)$ & Error rate (\%) \\
Vesic & 20 & 11.05 & 314.1 & 2.5 \\
Biot & 45 & 4.91 & 1590.4 & 0.2 \\
Biot & 20 & 11.05 & 314.1 & 2.5 \\
Elvadurai & 45 & 4.91 & 1590.4 & 0.2 \\
Elvadurai & 20 & 11.05 & 314.1 & 2.5 \\
Meyerhof \& Baike & 45 & 4.91 & 1590.4 & 0.2 \\
Meyerhof \& Baike & 20 & 11.05 & 314.1 & 2.5 \\
Galin & 45 & 4.91 & 1590.4 & 0.2 \\
Galin & 20 & 8.36 & 314.1 & 5.1 \\
Kameswara \& Rao & 45 & 6.58 & 1590.4 & 1.6 \\
Kameswara \& Rao & 20 & 11.05 & 314.1 & 2.5 \\
Klopple \& Glock & 45 & 4.91 & 1590.4 & 0.2 \\
Klopple \& Glock & 20 & 11.05 & 314.1 & 2.5 \\
This paper & 45 & 4.91 & 1590.4 & 0.2 \\
This paper & 20 & 12.93 & 314.1 & 1.9 \\
Real values & 45 & 4.80 & 1590.4 & 0.6 \\
Real values & 20 & 13.41 & 314.1 & 0.0 \\
\hline & 45 & 4.98 & 1590.4 & 0.0 \\
\hline
\end{tabular}

According to Figure 5 and Table 5, the power relation which was presented in figure 4 shows close results to PLTs values for different plates and seems very appropriate to generalize PLTsvalues to the original foundation size. 


\section{Generalizing the Results to Real Dimensions}

Figure 6 shows a new mathematical model to generalize PLTs results to real foundation. This model was drawn based on the power relation between Ks (yaxis) and foundation area ( $x$ axis) obtained in this article by changing the amount of (b) in figure 6 obtained equation (Eq. 5) in order to generalizing the results.

$y=433.98 x^{-0.611}+b$

After performing plate load test on the common plate such as $30 \mathrm{~cm}$, it can be possible by using figure 6 to generalize the result to real dimensions and find the value of Ks for real foundation.

Figure 6. Generalizing PLTs results to the real foundations dimensions.

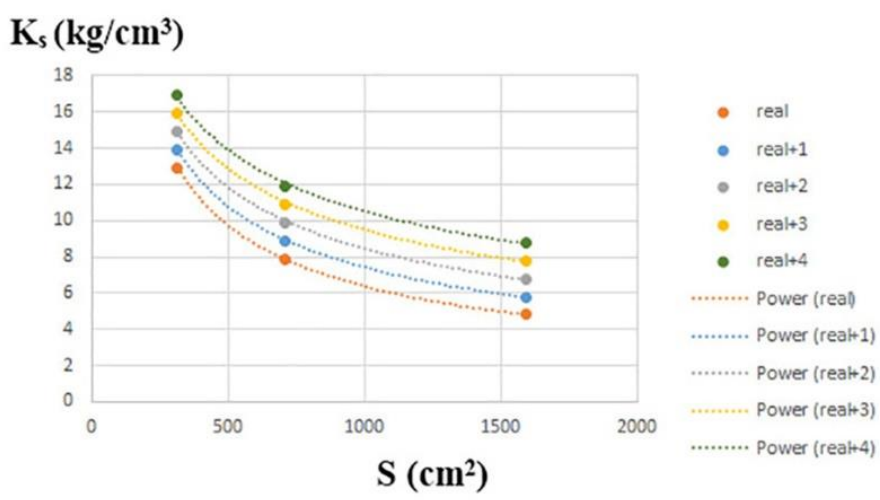

If the results of some tests are different to Figure 6, it is possible to draw more curves based on the mentioned method and predict the amount of Ks for real foundation.

\section{Conclusions}

The subgrade reaction modulus $(\mathrm{Ks})$ is one of the most important elements in geotechnical engineering to performfoundation dimensions and reinforcement calculations. To determine the coefficient, it is possible to use either the previously presented experimental relations or directly from field tests.In the present study, after performing 36 loading tests with 20,30 , and $45 \mathrm{~cm}$ diameters rigid steel plates and determining Ks and Es, also considering the area and geometrical properties of the foundation, a new equation was presented.Since the new equation involves soil stiffness and geometrical properties of the foundation, it can be a useful and valid reference for optimal structural calculations in the future. Then, after fitting statistical process on tests outputs and comparing results with previous experimental equations, a new mathematical model for generalizing the results ofPLTs to real dimensions of foundations in case of implementing plate load test was presented.

Barmenkova, E.V. \& Matveeda, A.V. (2015).Calculation of Variable Rigidity on Elastic Foundation with VariableCoefficient of Subgrade Reaction. Procedia Engineering, 111(3), 97-102.DOI: 10.1016/j.proeng.2015.07.058.

Bowels, J. (2001). Foundation Analysis and Design. McGraw- Hill, New York.

Das, B.M. (2016). Principles of Foundation Engineering (pp. 263-296). 8thedn, CENGAGE learning, United States.

Eslami, A. (2006). Foundation engineering design and construction. Building and Housing Research Center, BHRC.No.B-437, Tehran, Iran.

Fredlund, D.G., Rahardjo, H., \& Fredlund, M.D. (2012). Unsaturated Soil Mechanics in Engineering Practice. John Wiley \& Sons, Inc., Hoboken, New Jersey.

Isotalo, J. (2001). Basics of statistics. University of Tampere, Finland.

Mollahasani, A. (2008). Comparison of soil deformation coefficient with in-situ and laboratory PLT. (Unpublished master's thesis), Ferdowsi University of Mashhad, Mashhad, Iran.

Sepad Andish. (2015).Geotechnical reports. Sepad Andish Laboratory, Mashhad, Iran. 
Water Resources Management Department of the Ministry of Energy. (2005).PLTS on soil and soft rock, application, method and interpretation. Water Engineering standard, accessed June 2005. http://seso.moe.gov.ir

Wang, Y. (2009). Reliability-Based Economic Design Optimization of Spread Foundation. Journal of Geotechnical and Geoenvironmental EngineeringASCE, 135(7), 954-959.DOI: 10.1061/(ASCE)GT.1943-5606.0000013

Wang, Y., \& Kulhawy, F.H. (2008). Economic design Optimization of Foundation. Journal of Geotechnical and Geoenvironmental Engineering -ASCE, 134(8),1097-1105.DOI: 10.1061/(ASCE)1090-0241(2008)134:8(1097)

Winters, R., winters, A., \& Amedee, R.G. (2010).Statistics: A brief overview. Ochsner Journal,10(3),213-216.PMID: 21603381. 